\title{
Optimal management of cirrhotic ascites: A review for internal medicine physicians
}

\author{
Andrea Gallo ${ }^{1}$, Cristina Dedionigi ${ }^{1}$, Chiara Civitelli ${ }^{1}$, Anna Panzeri ${ }^{1,2}$, \\ Chiara Corradi ${ }^{2}$, Alessandro Squizzato ${ }^{1}$ \\ 'Department of Medicine and Surgery, University of Insubria, Como/Varese, Italy; \\ ${ }^{2}$ Hepatology Center, Ospedale Sant'Anna, Como, Italy
}

Address for Correspondence: Dr. Andrea Gallo MD, U.O. Medicina

1 Est

ASST Settelaghi, Viale Borri 57, 21100

Varese, Italy.

E-mail: andrea.gallo.89@hotmail.it

\begin{tabular}{|l|}
\hline Access this article online \\
\hline Website: \\
www.intern-med.com \\
DOI: \\
10.2478/jtim-2020-0035 \\
\hline Quick Response Code: \\
\hline \\
\end{tabular}

\section{ABSTRACT}

Clinical history of liver cirrhosis is characterised by two phases: the asymptomatic phase, also termed 'compensated cirrhosis', and the phase of complications due to the development of portal hypertension and liver dysfunction, also termed 'decompensated cirrhosis', in which patients may develop ascites, the most frequent and clinically relevant complication of liver cirrhosis. Ascites can be classified into uncomplicated and complicated according to the development of refractoriness, spontaneous bacterial peritonitis (SBP) or the association with hepatorenal syndrome (HRS). In this narrative review, we will extensively discuss the optimal pharmacological and non-pharmacological management of cirrhotic ascites with the aim to offer an updated practical guide to Internal Medicine physicians. According to the amount of fluid in the abdominal cavity, uncomplicated ascites is graded from 1 to 3 , and the cornerstone of its management consists of restriction of salt intake, diuretics and large-volume paracentesis (LVP); in recent years, long-term administration of human albumin has acquired a new interesting role. Refractory ascites is primarily managed with LVP and transjugular intrahepatic portosystemic shunt (TIPS) placement in selected patients. The occurrence of renal impairment, especially HRS, worsens the prognosis of patients with cirrhotic ascites and deserves a specific treatment. Also, the management of SBP faces the rising and alarming spread of antibiotic resistance. Hepatic hydrothorax may even complicate the course of the disease and its management is a challenge. Last but not least, liver transplantation (LT) is the ultimate and more effective measure to offer to patients with cirrhotic ascites, particularly when complications occur.

Key words: liver cirrhosis, ascites, hepatorenal syndrome, spontaneous bacterial peritonitis, hepatic hydrothorax, human albumin, narrative review

\section{INTRODUCTION}

Chronic liver disease may irreversibly lead to cirrhosis. ${ }^{[1]}$ Inflammation, fibrosis and regenerative necrotic events are the main underlying pathogenetic processes. ${ }^{[2]}$ Clinical history is characterised by two phases: the asymptomatic phase, also termed 'compensated cirrhosis', and the phase of complications due to the development of portal hypertension and liver dysfunction, also termed 'decompensated cirrhosis', in which patients may develop ascites, portal hypertensive gastrointestinal bleeding, encephalopathy, jaundice, hepatorenal syndrome (HRS), hepatopulmonary syndrome, spontaneous bacterial peritonitis (SBP) and/or hepatocellular carcinoma (HCC). ${ }^{[3,4]}$ Ascites is certainly the most frequent and clinically relevant complication. In this narrative review, we will extensively discuss updated evidence on the optimal pharmacological and non-pharmacological management of cirrhotic ascites.

\section{PATHOPHYSIOLOGY OF CIRRHOTIC ASCITES}

Ascites is the presence of fluid in the peritoneal cavity. Almost $60 \%$ of patients develop ascites within 10 years from the diagnosis of cirrhosis. ${ }^{[5]}$ Portal hypertension 
is the main underlying pathogenetic event that leads to ascites. ${ }^{[6]}$ Albumin is exclusively synthesised by hepatocytes and, ${ }^{[7]}$ therefore, liver function impairment leads to hypoalbuminaemia; ${ }^{[8]}$ however, hypoalbuminaemia per se is not the main driver for ascites formation: experimental models demonstrated that in patients with cirrhosis and ascites, the colloid osmotic pressure of plasma remains higher than that of ascitic fluid (19.9 $\pm 0.5 v s$. $4.8 \pm 1.0 \mathrm{mmHg}){ }^{[9]}$ According to the peripheral arterial vasodilatation hypothesis, portal hypertension causes an increase of vasodilators in the blood stream and a consequent reduction of effective circulating volume. It results in an activation of sympathetic nervous system (SNS), renin-angiotensin-aldosterone system (RAAS), non-osmotic secretion of vasopressin and a consequent water and sodium retention that provokes a fluid transition to the extravascular space, in particular, to the peritoneal cavity. ${ }^{[6]}$ Another source of vasodilators may be the gut, in which bacterial overgrowth and intestinal dysbiosis may cause intestinal inflammation and breakdown of the intestinal barrier. Bacterial products may stimulate the release of proinflammatory cytokines that increase splanchnic arterial vasodilatation. ${ }^{[10]}$

\section{CLINICAL FEATURES AND PROGNOSIS OF CIRRHOTIC ASCITES}

According to the amount of fluid in the abdominal cavity, cirrhotic ascites is graded as follows: mild - grade 1 , if detectable only by ultrasound; moderate - grade 2 , if it causes symmetrical distension of the abdomen and tense - grade 3, if it causes marked abdominal distension. Moreover, ascites can be classified into uncomplicated and complicated according to the development of refractoriness, SBP or the association with HRS. ${ }^{[5,6]}$

Refractory ascites is defined as ascites that cannot be mobilised or the early recurrence because of a lack of response to medical therapy. Refractory ascites includes diuretic-resistant ascites and diuretic-intractable ascites: these terms describe the failure of diuretic therapy due to unsatisfactory efficacy and development of unacceptable side effects, respectively. ${ }^{[11]}$

Finally, ascites is defined as 'recidivant' when it occurs at least three times in 12 months despite the optimisation of therapy. ${ }^{[12]}$ A complete list of definitions is shown in Table 1.

Beyond physical examination, complete blood and urine tests and abdominal ultrasound, physicians should perform diagnostic paracentesis in every patient with a new-onset ascites of grade 2 or 3 or acutely decompensated. ${ }^{[13,14]}$ Peritoneal fluid analysis includes neutrophil count, total protein and albumin concentration, which allow to distinguish cirrhotic ascites from ascites due to other aetiologies; notably, cirrhosis is the main cause of ascites, being responsible for about $80 \%$ of cases. ${ }^{[15]}$ Moreover, peritoneal fluid analysis allows to diagnose SBP and provide important prognostic information. ${ }^{[13,14]}$

Ascites is associated with poor quality of life and 2- and 5 -year mortality rates at $38 \%$ and $78 \%$, respectively, after its occurrence. ${ }^{[16]}$ The median survival for patients with compensated cirrhosis is 12 years and for decompensated cirrhosis 2 years. ${ }^{[17]}$ Main poor prognosis predictors are hyponatraemia, low arterial pressure, increased serum creatinine and low urine sodium. ${ }^{[18]}$

\section{MANAGEMENT OF CIRRHOTIC ASCITES}

Table 2 lists a summary of selected recommendations from 2018 European Association for the Study of the Liver (EASL) guidelines and 2012 American Association for the Study of Liver Diseases (AASLD) guidelines.

\section{Management of uncomplicated ascites GRADE 1}

No specific pharmacological treatment is suggested in grade 1 ascites ${ }^{[13]}$ because no treatment has definitely been shown to modify natural history. The first step is to treat the underlying liver disease, ${ }^{[13,14]}$ in particular, stopping alcohol consumption when present; abstinence dramatically improves the reversible component of alcoholic liver disease. ${ }^{[19]}$ Also, viral hepatitis and autoimmune hepatitis can have a dramatic response; conversely, other liver diseases are less reversible. ${ }^{[14]}$

\section{GRADE 2}

\section{Bed rest}

Bed rest was previously recommended based on the assumption that upright position further increases plasma renin levels. ${ }^{[20,21]}$ There is currently insufficient published evidence to routinely recommend bed rest to all patients. ${ }^{[13]}$

\section{Sodium restriction and nutrition}

Although there is no clear evidence, current guidelines suggest a moderate restriction of dietary salt $(88 \mathrm{mmol}$ of sodium/day, equivalent to $2 \mathrm{~g}$ of salt/day) $\cdot^{[13,14]}$ Moreover, fluid intake should be restricted only in patients with dilutional hyponatraemia (sodium $<130 \mathrm{mEq} / \mathrm{L}$ ). ${ }^{[13,14]}$ However, published evidence shows a relationship between lower salt intake (in particular, sodium $<50 \mathrm{mmol} /$ day) and malnutrition (due to a lower caloric intake), diuretic-induced hyponatraemia and renal failure. ${ }^{[22,23]}$ Indeed, malnutrition is associated with infection, ${ }^{[24]}$ recurrence of ascites, ${ }^{[2]]}$ hepatic encephalopathy ${ }^{[26]}$ and poor prognosis. ${ }^{[27]}$ In recent years, malnutrition has also been found to be associated with obesity and sarcopenic obesity. ${ }^{[28,29]}$ Therefore, guidelines 
Gallo et al: : Optimal management of cirrhotic ascites: A review for internal medicine physicians

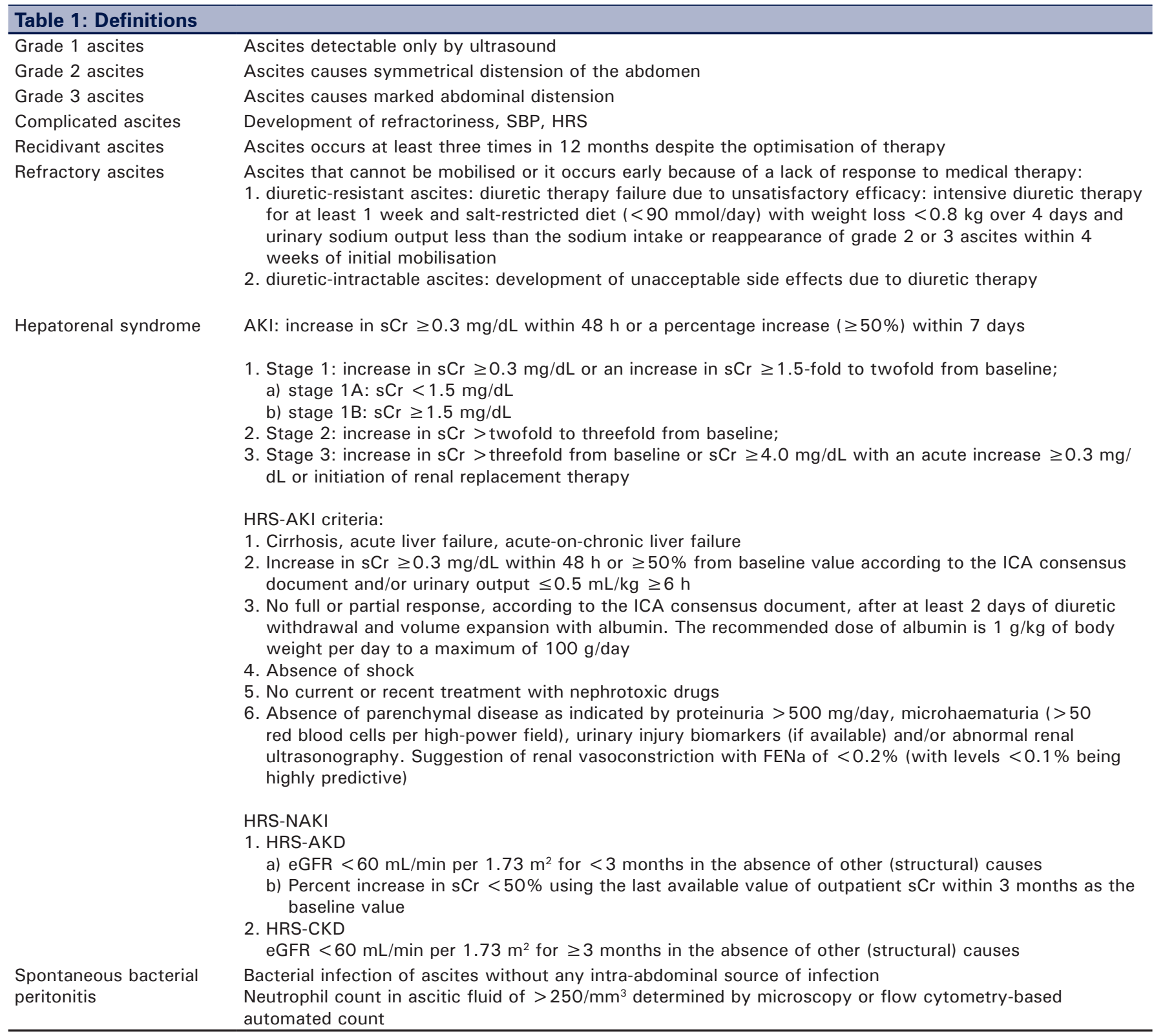

SBP: spontaneous bacterial peritonitis; HRS: hepatorenal syndrome; AKI: acute kidney injury; sCr: serum creatinine; ICA: International Club of Ascites; FENa: fractional excretion of sodium; NAKI: non-acute kidney injury; AKD: acute kidney disease; eGFR: estimated glomerular filtration rate; CKD: chronic kidney disease

suggest to examine all patients with advanced chronic liver disease with a rapid nutritional screen and to ensure an optimal daily energy and protein intake of $35 \mathrm{kcal} / \mathrm{kg}$ actual body weight/day and 1.2-1.5 g/ kg actual body weight/day, respectively, in order to avoid malnutrition. ${ }^{[30]}$

\section{Diuretics}

Diuretics are a cornerstone of ascites management; they are used for symptomatic treatment to induce negative fluid balance. The activation of RAAS and the consequent increase of aldosterone lead to the retention of water and sodium by proximal and distal renal tubules. ${ }^{[31]}$ For this reason, aldosterone antagonists (e.g. spironolactone) are more effective than loop diuretics or other potassiumsparing diuretics. ${ }^{[32]}$ The initial dose should be 100-200 $\mathrm{mg} /$ day and can be increased up to $400 \mathrm{mg} /$ day. ${ }^{[13]}$

Furosemide (from 40 to $160 \mathrm{mg}$ ) can be combined with aldosterone antagonists ${ }^{[13]}$ to increase the amount of sodium that reaches the distal tubule, and therefore, it indirectly increases the effectiveness of spironolactone. The combination of aldosterone antagonists and loop diuretics is effective in a shorter period of time and is safer than sequential diuretic therapy. ${ }^{[33,34]}$ 
Table 2: Summary of selected recommendations about treatment of cirrhotic ascites and its complication from 2018 EASL guidelines and 2012 AASLD guidelines (details in the main text)

EASL 2018

Rational behind grading system for recommendations

Level of evidence

I Randomised, controlled trials

II-1 Controlled trials without randomisation

II-2 Cohort and case-control analytical studies

II-3 Multiple time series, dramatic uncontrolled experiments

III Opinions of respected authorities, descriptive epidemiology

Grade of recommendations

1 Strong recommendations: Factors influencing the strength of the recommendation included the quality of the evidence, presumed patient-important outcomes and cost

2 Weaker recommendations: Variability in preferences and values, or more uncertainty: a weak recommendation is warranted more likely. Recommendation is made with less certainty: higher cost or resource consumption

Treatment of the underlying disease

The aetiological factors should be removed, particularly alcohol consumption and hepatitis $B$ or $C$ virus infections (II- $2 ; 1)$

First-line treatment Prolonged bed rest cannot be recommended (III; 1 ) (bed rest, sodium restriction, diuretics) A moderate restriction of sodium intake is recommended in patients with moderate, uncomplicated ascites $(I ; 1)$

Diets with a very low sodium content ( $<40 \mathrm{mmol} / \mathrm{day})$ should be avoided (II- $2 ; 1)$

Patients with the first episode of grade 2 (moderate) ascites should receive an anti-mineralocorticoid drug alone $(1 ; 1)$

In patients who do not respond to antimineralocorticoids, furosemide should be added $(I ; 1)$

During diuretic therapy, a maximum weight loss of 0.5 $\mathrm{kg} /$ day in patients without oedema and $1 \mathrm{~kg} /$ day in patients with oedema is recommended $(\mathrm{II}-2 ; 1)$

Once ascites has largely resolved, the dose of diuretics should be reduced to the lowest effective dose $($ III; 1$)$

Diuretics should be discontinued in patients with refractory ascites who do not excrete $>30 \mathrm{mmol} / \mathrm{day}$ of sodium under diuretic treatment $(\mathrm{III} ; 1)$

\section{AASLD 2012}

Class of recommendation:

Class I Conditions for which there is evidence and/or general agreement that a given diagnostic evaluation, procedure or treatment is beneficial, useful and effective

Class II Conditions for which there is conflicting evidence and/or a divergence of opinion about the usefulness/efficacy of a diagnostic evaluation, procedure or treatment

Class Ila Weight of evidence/opinion is in favour of usefulness/efficacy

Class Ilb Usefulness/efficacy is less well established by evidence/opinion

Class III Conditions for which there is evidence and/ or general agreement that a diagnostic evaluation/ procedure/treatment is not useful/effective and, in some cases, may be harmful

Level of evidence

Level A Data derived from multiple randomised clinical trials or meta-analyses

Level B Data derived from a single randomised trial or nonrandomised studies

Level C Only consensus opinion of experts, case studies or standard of care

Patients with ascites who are thought to have an alcohol component to their liver injury should abstain from alcohol consumption (Class I, Level B)

First-line treatment of patients with cirrhosis and ascites consists of sodium restriction $(88 \mathrm{mmol} / \mathrm{day}$ [2000 mg/day], diet education) and diuretics (oral spironolactone with or without oral furosemide) (Class Ila, Level A)

Fluid restriction is not necessary unless serum sodium is less than $125 \mathrm{mmol} / \mathrm{L}$ (Class III, Level C) 
Table 2: Summary of selected recommendations about treatment of cirrhotic ascites and its complication from 2018 EASL guidelines and 2012 AASLD guidelines (details in the main text)

EASL 2018

LVP

LVP is the first-line therapy in patients with large ascites (grade 3 ascites), which should be completely removed in a single session $(1 ; 1)$

In patients undergoing LVP of $>5 \mathrm{~L}$ of ascites, plasma volume expansion should be performed by infusing albumin, as it is more effective than other plasma expanders $(I ; 1)$

In patients undergoing LVP of $<5 \mathrm{~L}$ of ascites, it is generally agreed that these patients should still be treated with albumin (III;1)

After LVP, patients should receive the minimum dose of diuretics necessary to prevent re-accumulation of ascites $(\mathrm{l} ; 1)$

Repeated LVP plus albumin are recommended as the first-line treatment for refractory ascites $(I ; 1)$

NSBBs

TIPS

Other medical treatments

Alfapump ${ }^{\oplus y s t e m}$ LT
Although controversial data exist on the use of NSBBs in refractory ascites, caution should be exercised in cases of severe or refractory ascites. High doses of NSBB should be avoided (i.e. propranolol $>80 \mathrm{mg} /$ day) (II-2;1)

The use of carvedilol cannot be recommended at present $(1 ; 2)$

Patients with refractory or recurrent ascites $(I ; 1)$ or those for whom paracentesis is ineffective should be evaluated for TIPS insertion (III; 1)

TIPS insertion is recommended in patients with recurrent ascites $(I ; 1)$ as it improves survival $(I ; 1)$ and in patients with refractory ascites as it improves the control of ascites $(I ; 1)$

The use of small-diameter PTFE-covered stents is recommended to reduce the risk of TIPS dysfunction and hepatic encephalopathy is recommended $(I ; 1)$

Careful selection of patients for elective TIPS insertion is crucial (III; 1$)$

At present, the addition of clonidine or midodrine to diuretic treatment cannot be recommended (III;1)

Alfapump implantation in patients with refractory ascites not amenable to TIPS insertion is suggested in experienced centres $(1 ; 2)$

Since the development of grade 2 or 3 ascites in patients with cirrhosis is associated with reduced survival, LT should be considered as a potential treatment option (II-2;1)

Patients with refractory ascites should be evaluated for LT (III; 1)
AASLD 2012

Paracentesis should be performed in patients with tense ascites. Sodium restriction and oral diuretics should then be initiated (Class Ila, Level C)

For LVP, an albumin infusion of $6-8 \mathrm{~g} / \mathrm{L}$ of fluid removed appears to improve survival and is recommended (Class Ila, Level A)

Post-paracentesis albumin infusion may not be necessary for a single paracentesis of less than 4 to 5 L (Class I, Level C)

Diuretic-sensitive patients should preferably be treated with sodium restriction and oral diuretics rather than with serial paracentesis (Class Ila, Level C)

Serial therapeutic paracentesis is a treatment option for patients with refractory ascites (Class I, Level C)

Routine prophylactic use of fresh frozen plasma or platelets is not recommended before paracentesis (Class III, Level C)

The risks versus benefits of beta blockers must be carefully weighed in each patient with refractory ascites. Consideration should be given to discontinuing or not initiating these drugs in this setting (Class III, Level B)

TIPS may be considered in appropriately selected patients who meet the criteria similar to those of published randomised trials (Class I, Level A)

Oral midodrine should be considered in in patients with refractory ascites (Class Ila, Level B)

Vaptans' use does not currently appear justified (Class III, Level A)

LT should be considered in patients with cirrhosis and ascites (Class I, Level B)

Referral for LT should be expedited in patients with refractory ascites, if the patient is otherwise a candidate for transplantation (Class Ila, Level C) 
Table 2: Summary of selected recommendations about treatment of cirrhotic ascites and its complication from 2018 EASL guidelines and 2012 AASLD guidelines (details in the main text)

HRS $\quad$ Vasoconstrictors and albumin are recommended in all patients meeting the current definition of AKI-HRS stage $>1 \mathrm{~A}(\mathrm{III} ; 1)$

Terlipressin plus albumin should be considered as the first-line therapeutic option for the treatment of HRS-AKI $(\mathrm{l} ; 1)$

Albumin solution $(20 \%)$ should be used at the dose of $20-40 \mathrm{~g} /$ day $(\mathrm{II}-2 ; 1)$

Noradrenaline can be an alternative to terlipressin $(1 ; 2)$

Midodrine plus octreotide can be an option only when terlipressin or noradrenaline is unavailable, but its efficacy is much lower than that of terlipressin $(1 ; 1)$

Vasoconstrictors and albumin are not recommended in HRS-NAKI $(1 ; 1)$

Third-generation cephalosporins are recommended as the first-line antibiotic treatment for community-acquired SBP in countries with low rates of bacterial resistance $(I ; 1)$

In countries with high rates of bacterial resistance, piperacillin/tazobactam or carbapenem should be considered (II-2;1)

For healthcare-associated and nosocomial SBP, piperacillin/tazobactam should be given in areas with low prevalence of MDRs, while carbapenem should be used in areas with high prevalence of ESBL producing Enterobacteriaceae. Carbapenem should be combined with glycopeptides or daptomycin or linezolid in areas with high prevalence of gram-positive MDR bacteria $(I ; 1)$

De-escalation according to bacterial susceptibility based on positive cultures is recommended to minimise resistance selection pressure $(\mathrm{II}-2 ; 1)$

The efficacy of antibiotic therapy should be checked with a second paracentesis at $48 \mathrm{~h}$ from starting treatment $(\mathrm{II}-2 ; 1)$

The duration of treatment should be at least 5-7 days (III; 1 )

Administration of albumin $(1.5 \mathrm{~g} / \mathrm{kg}$ at diagnosis and $1 \mathrm{~g} /$ $\mathrm{kg}$ on day 3$)$ is recommended in patients with $\operatorname{SBP}(1 ; 1)$

Primary prophylaxis with norfloxacin $(400 \mathrm{mg} /$ day) in patients with Child-Pugh score $\geq 9$ and serum bilirubin level $\geq 3 \mathrm{mg} / \mathrm{dL}$, with either impaired renal function or hyponatraemia, and ascitic fluid protein lower than 15 $\mathrm{g} / \mathrm{L}$ is recommended $(\mathrm{I} ; 1)$

Norfloxacin prophylaxis should be stopped in patients with long-lasting improvement of their clinical condition and disappearance of ascites (III; 1 )

Administration of prophylactic norfloxacin $(400 \mathrm{mg} / \mathrm{day}$, orally) is recommended in patients who recover from an episode of SBP $(1 ; 1)$
AASLD 2012

Albumin infusion plus administration of vasoactive drugs such as octreotide and midodrine should be considered in the treatment of type I HRS (Class Ila, Level B)

Albumin infusion plus administration of norepinephrine should also be considered in the treatment of type HRS, when the patient is in the intensive care unit (Class Ila, Level A)

Patients with cirrhosis, ascites and type I or type II HRS should have an expedited referral for LT (Class I, Level B)

Patients with ascitic fluid PMN leucocyte counts $\geq 250$ cells $/ \mathrm{mm}^{3}$ in a community-acquired setting in the absence of recent $\beta$-lactam antibiotic exposure should receive empiric antibiotic therapy, for example, intravenous third-generation cephalosporin, preferably cefotaxime $2 \mathrm{~g}$ every $8 \mathrm{~h}$ (Class I, Level A)

Patients with ascitic fluid PMN leucocyte counts $\geq 250$ cells $/ \mathrm{mm}^{3}$ in a nosocomial setting and/or in the presence of recent b-lactam antibiotic exposure should receive empiric antibiotic therapy based on local susceptibility testing of bacteria in patients with cirrhosis (Class Ila, Level B)

Oral ofloxacin ( $400 \mathrm{mg}$ twice per day) can be considered a substitute for intravenous cefotaxime in inpatients without prior exposure to quinolones, vomiting, shock, grade II (or higher) hepatic encephalopathy or serum creatinine $>3 \mathrm{mg} / \mathrm{dL}$ (Class Ila, Level B)

Patients with ascitic fluid PMN leucocyte counts $<250$ cells $/ \mathrm{mm}^{3}$ and signs or symptoms of infection should also receive empiric antibiotic therapy, for example, intravenous cefotaxime 2 g every 8 h, while awaiting results of cultures (Class I, Level B)

Patients with ascitic fluid PMN leucocyte counts $\geq 250$ cells $/ \mathrm{mm}^{3}$ with serum creatinine $>1 \mathrm{mg} / \mathrm{dL}$, blood urea nitrogen $>30 \mathrm{mg} / \mathrm{dL}$ or total bilirubin $>4$ $\mathrm{mg} / \mathrm{dL}$ should receive albumin $1.5 \mathrm{~g} / \mathrm{kg}$ within $6 \mathrm{~h}$ and $1.0 \mathrm{~g} / \mathrm{kg}$ on day 3 (Class Ila, Level B)

Patients who have survived an episode of SBP should receive long-term prophylaxis with daily norfloxacin (or trimethoprim/sulfamethoxazole) (Class I, Level A)

In patients with cirrhosis and ascites, long-term use of norfloxacin (or trimethoprim/sulfamethoxazole) can be justified if the ascitic fluid protein is $<1.5 \mathrm{~g} / \mathrm{dL}$ along with impaired renal function (creatinine $\geq 1.2$, BUN $\geq 25$ or serum sodium $\leq 130$ ) or liver failure (Child score $\geq 9$ and bilirubin $\geq 3$ ) (Class I, Level A) 
Gallo et al: : Optimal management of cirrhotic ascites: A review for internal medicine physicians

\begin{tabular}{|c|c|c|}
\hline & EASL 2018 & AASLD 2012 \\
\hline \multirow[t]{6}{*}{$\begin{array}{l}\text { Hepatic } \\
\text { hydrothorax }\end{array}$} & $\begin{array}{l}\text { Diuretics and thoracentesis are recommended as the } \\
\text { first-line management of hepatic hydrothorax }(I I I ; 1)\end{array}$ & $\begin{array}{l}\text { Chest tube insertion is contraindicated in patients } \\
\text { with hepatic hydrothorax (Class III, Level B) }\end{array}$ \\
\hline & $\begin{array}{l}\text { Chronic pleural should not be performed because of the } \\
\text { frequent occurrence of complications }(\mathrm{II}-2 ; 1)\end{array}$ & $\begin{array}{l}\text { First-line therapy of hepatic hydrothorax consists of } \\
\text { sodium restriction and diuretics (Class Ila, Level B) }\end{array}$ \\
\hline & $\begin{array}{l}\text { In selected patients, TIPS insertion for recurrent } \\
\text { symptomatic hepatic hydrothorax is recommended } \\
(\text { II- } 2 ; 1)\end{array}$ & $\begin{array}{l}\text { TIPS can be considered as the second-line treatment } \\
\text { for hepatic hydrothorax, once it becomes refractory } \\
\text { (Class Ilb, Level B) }\end{array}$ \\
\hline & $\begin{array}{l}\text { Pleurodesis can be suggested for patients with } \\
\text { refractory hepatic hydrothorax not amenable to LT or } \\
\text { TIPS insertion. However, the frequent occurrence of } \\
\text { side effects related to this technique restricts its use to } \\
\text { selected patients }(1 ; 2)\end{array}$ & \\
\hline & $\begin{array}{l}\text { Mesh repair of diaphragmatic defects is suggested in } \\
\text { very selected patients. Without advanced cirrhosis and } \\
\text { renal dysfunction (II-2;2) }\end{array}$ & \\
\hline & $\begin{array}{l}\text { Patients with hydrothorax should be evaluated for } \\
\text { LT }(I I I ; 1)\end{array}$ & \\
\hline
\end{tabular}

PTFE: polytetrafluoroethylene; AKI: acute kidney injury; NAKI: non-acute kidney injury; PMN: polymorphonuclear; MDRs: multidrug-resistant bacteria; ESBL: extended-spectrum $\beta$-lactamase; BUN: blood urea nitrogen; TIPS: transjugular intrahepatic portosystemic shunt; LT: liver transplantation; SBP: spontaneous bacterial peritonitis; NSBBs: nonselective beta-blockers; LVP: large-volume paracentesis; HRS: hepatorenal syndrome; EASL: European Association for the Study of the Liver; AASLD: American Association for the Study of Liver Diseases

The aim is to achieve a body weight reduction of more than $1 \mathrm{~kg} /$ week until ascites is controlled. Weight loss should be less than $500 \mathrm{~g} /$ day in patients without peripheral oedema ${ }^{[13]}$ in order to avoid side effects such as renal impairment, ${ }^{[35,36]}$ hepatic encephalopathy, ${ }^{[37]}$ hyponatraemia, hypokalaemia, hypomagnesaemia ${ }^{[38]}$ and muscle cramps; notably, the last one can be successfully treated with human albumin (HA) infusion. In a small trial, albumin was found to reduce the frequency of cramps compared with placebo by $2.5 \pm 2.9$ episodes/week. ${ }^{[39]}$ Moreover, baclofen also may be effective in mitigating muscle cramps. ${ }^{[40]}$

Once ascites disappears, diuretic therapy should be administered at the minimum effective dose to avoid recurrences. ${ }^{[13]}$

\section{GRADE 3}

Large-volume paracentesis

Large-volume paracentesis (LVP) is the first-line therapy in patients with grade 3 ascites which should be completely removed in a single session. ${ }^{[13,14]}$

Physicians should not perform paracentesis in case of uncooperative patient, abdominal skin infection at the proposed puncture sites, pregnancy or severe bowel distension. ${ }^{[13]}$ Despite the fact that underlying coagulopathy is common, LVP is safe; overall, the frequency of bleeding complication is estimated to be $1 \%-3 \%,{ }^{[11,42]}$ and therefore, international guidelines suggest not to perform paracentesis just in case of severe coagulopathy such as accelerated fibrinolysis or disseminated intravascular coagulation. ${ }^{[13]}$

The removal of a large volume of ascitic fluid is potentially associated with further reduction of effective blood volume. This condition is known as post-paracentesis circulatory dysfunction (PPCD), ${ }^{[43]}$ which is associated with rapid recurrence of ascites, high incidence of HRS, hyponatraemia and death. ${ }^{[4]]}$ Plasma volume expansion should be performed at the completion of LVP greater than $5 \mathrm{~L}$ of ascites ${ }^{[13]}$ by infusing albumin $(8 \mathrm{~g}$ for any litre of ascites removed), as it is more effective than other plasma expanders. ${ }^{[45]}$ European guidelines suggest to administer albumin also after removal of less than $5 \mathrm{~L}$ of ascites, ${ }^{[13]}$ while American guidelines do not. ${ }^{[14]}$ However, LVP does not modify the underlying pathophysiological abnormalities leading to ascites formation.

\section{Diuretics}

After LVP, patients should receive the minimum dose of diuretics necessary to prevent re-accumulation of ascites. ${ }^{[13]}$

\section{Albumin}

Albumin is the most abundant protein in serum and extracellular fluids. ${ }^{[4]}$ Albumin plays a central role in maintaining plasma oncotic pressure; moreover, it has other important properties, that is, as an antioxidant and 
a scavenging, immune-modulating and endotheliumprotective molecule. ${ }^{[7,47]}$

Liver cirrhosis does not only reduce the quantity of albumin, but also its quality. The proinflammatory and pro-oxidant state of decompensated cirrhosis affects the function and structure of albumin. ${ }^{[10,48]}$ The amount of proteins with intact structure and function is called 'effective albumin concentration'. ${ }^{[4,50]}$

HA is a multi-target agent and is now considered a diseasemodifying treatment in patients with decompensated cirrhosis. The role of HA administration in patients with ascites who undergo LVP or suffer from HRS type 1 or SBP has been well established and is already recognised by guidelines. ${ }^{[13,14]}$ Beyond these conditions, recent studies suggest that long-term administration of HA could have a pivotal role in the treatment of uncomplicated ascites. HA administration improves effective blood volume by attenuating peripheral arterial vasodilation, prevents renal dysfunction, enhances cardiac inotropism and reduces systemic inflammation and endothelial dysfunction by acting as an antioxidant agent. ${ }^{[50-53]}$ Table 3 lists the indications for $\mathrm{HA}$ administration, dosage and corresponding rational.

In 1999, Gentilini and colleagues provided the first trial which demonstrated the beneficial effect of long-term administration of HA. ${ }^{[54]}$ Seven years later, Romanelli and colleagues published the first study that showed improved survival of patients with cirrhotic ascites receiving longterm HA; however, this study was not powered enough to provide definitive evidence and this promising therapeutic strategy was not included in guidelines. ${ }^{[55]}$ In recent years, the ANSWER study enrolled 431 patients with grade 2 or 3 non-refractory ascites and compared standard medical treatment (SMT) alone with SMT and HA (40 g twice a week for 2 weeks and then $40 \mathrm{~g}$ weekly up to 18 months). Patients in the treatment group showed an overall survival which was significantly higher than in the control group $(77 \%$ vs. $66 \%)$ during the treatment period. Moreover, patients treated with albumin experienced fewer episodes of SBP, sepsis, HRS type 1 and hepatic encephalopathy grade; finally, HA administration reduced the evolution rate to refractory ascites and the need for paracentesis. ${ }^{[56]}$

A post hoc analysis of the ANSWER study showed that the 18-month survival was $93 \%$ in patients with 1 -month serum albumin (SA) level $>4.1 \mathrm{~g} / \mathrm{dL}$ and $70 \%$ in those with 1 -month $\mathrm{SA} \leq 4.1 \mathrm{~g} / \mathrm{dL}$. Patients not reaching the SA thresholds had lower SA at baseline and higher model of end-stage liver disease (MELD) score. Moreover, HA treatment was the most powerful predictor of reaching this threshold (odds ratio [OR] 33.69 [95\% CI 10.0-113.1]).
Therefore, the SA level at baseline and during treatment may predict patient outcomes, and the latter value may be influenced by HA administration. ${ }^{[5]}$

The MATCH study enrolled 173 patients with cirrhotic ascites awaiting liver transplantation (LT). Patients in the treatment arm received midodrine $15-30 \mathrm{mg}$ /day and HA $40 \mathrm{~g}$ every 15 days, while patients in the control arm received matching placebo for 1 year or until LT. The study treatment was not significantly different from placebo in improving survival (during the follow-up period, $7 \%$ and $5 \%$ of patients died in the treatment group and in the placebo group, respectively; $P=0.527$ ) or in the prevention any complications of cirrhosis $37 \%$ and $43 \%$ of patients developed complications in the treatment group and in the placebo group, respectively; $P=0.402$ ); there was not a reduction either in the dose of diuretic treatment or in the requirement of LVP with HA and midodrine. However, the episodes of hyponatraemia and renal failure were more severe in the placebo group. ${ }^{[58]}$

Notably, the treatment duration was shorter than expected: a median of 80 days in the entire population and 63 days in the midodrine and HA group; 68\% from the treatment group and 55\% from the placebo group were transplanted at a median of 42 days and only nine patients received the treatment for 1 year as prevented.

Moreover, compared with the ANSWER study, in the MATCH study, the total amount of HA administered was lower and the increase in SA level was not significantly different between the two groups. Patients enrolled in the MATCH study were sicker than in the ANSWER trial as demonstrated by a higher median MELD score (17 vs. 13) which is connected with a lower 'effective albumin concentration'. ${ }^{\text {[48] }}$

Long-term HA administration requires an effort by healthcare services and patient compliance. However, it is associated with a better quality of life because of fewer hospital admissions and lesser need for medical intervention, contributing to a favourable cost-effectiveness ratio.

Overall, HA may be defined as a disease-modifying treatment in patients with decompensated cirrhosis and, despite many clinical issues that still need to be clarified and investigated, available evidence supports long-term HA administration in patients with uncomplicated ascites.

Transjugular intrahepatic portosystemic shunt Transjugular intrahepatic portosystemic shunt (TIPS) is the catheterisation of a hepatic vein by the transjugular approach while the patient is under local anaesthesia, 
Gallo et al: : Optimal management of cirrhotic ascites: A review for internal medicine physicians

\begin{tabular}{|c|c|c|}
\hline Indication & $\begin{array}{l}\text { Dosage of administration of } \\
\text { albumin } 20 \%\end{array}$ & Rational \\
\hline Post-paracentesis & $8 \mathrm{~g} / \mathrm{L}$ of ascites removed & $\begin{array}{l}\text { To prevent further reduction of effective blood volume (post- } \\
\text { paracentesis circulatory dysfunction) }\end{array}$ \\
\hline Muscle cramps & $\begin{array}{l}25 \mathrm{~g} \text { once a week for } 4 \\
\text { weeks }\end{array}$ & $\begin{array}{l}\text { To reduce the frequency of muscle cramps by improving effective } \\
\text { circulating volume }\end{array}$ \\
\hline $\begin{array}{l}\text { Long-term administration } \\
\text { (in particular, in patients with } \\
\text { uncomplicated ascites) }\end{array}$ & $\begin{array}{l}40 \mathrm{~g} \text { twice a week for } 2 \\
\text { weeks and then } 40 \mathrm{~g} \text { weekly }\end{array}$ & $\begin{array}{l}\text { Human albumin administration improves effective blood volume } \\
\text { by attenuating peripheral arterial vasodilation, prevents renal } \\
\text { dysfunction, enhances cardiac inotropism and reduces systemic } \\
\text { inflammation and endothelial dysfunction, acting as an antioxidant } \\
\text { agent. This leads to an improvement of survival and a reduction } \\
\text { in the occurrence of spontaneous bacterial peritonitis, sepsis, } \\
\text { hepatorenal syndrome type } 1 \text {, hepatic encephalopathy grade, as } \\
\text { well as the evolution rate to refractory ascites and the need of } \\
\text { paracentesis }\end{array}$ \\
\hline $\begin{array}{l}\text { Renal impairment (AKI stage } \\
>1 \mathrm{~A} \text { without obvious cause) }\end{array}$ & $\begin{array}{l}1 \mathrm{~g} / \mathrm{kg} \text { body weight for two } \\
\text { consecutive days }\end{array}$ & Human albumin prevents HRS-AKI occurrence \\
\hline HRS-AKI & $20-40 \mathrm{~g} /$ day & $\begin{array}{l}\text { Human albumin reduces systemic inflammation and microvascular } \\
\text { dysfunction, besides improving blood volume }\end{array}$ \\
\hline SBP & $\begin{array}{l}1.5 \mathrm{~g} / \mathrm{kg} \text { at diagnosis and } 1 \\
\mathrm{~g} / \mathrm{kg} \text { on day } 3\end{array}$ & Human albumin prevents HRS-AKI occurrence \\
\hline
\end{tabular}

AKI: acute kidney injury; HRS: hepatorenal syndrome; SBP: spontaneous bacterial peritonitis

followed by placement of a stent to connect portal and systemic blood systems. Potential complications include encephalopathy, heart and liver failure. ${ }^{[59]}$

The most important indication to TIPS is the prevention of variceal bleeding. ${ }^{[13]}$ Regarding management of ascites, this treatment option was mostly studied in refractory ascites: among six prospective randomised controlled trials (RCTs) available which compared TIPS versus LVP, only two included patients with recurrent ascites. ${ }^{[60,61]}$ Interestingly, a meta-analysis of all six studies globally failed to demonstrate a survival advantage with TIPS (OR 0.82; 95\% CI 0.46-1.50), while in the subgroups of patients with recurrent ascites, an increased survival with TIPS was found (OR 0.45; 95\% CI 0.24--0.81). ${ }^{[62]}$ The beneficial effect of TIPS in patients with recurrent ascites was confirmed by a recent trial performed by Bureau and colleagues. ${ }^{[63]}$ These data suggest that cirrhotic patients with a better clinical status, in terms of liver and renal function, may survive longer than cirrhotic patients with a worse status. However, more data are warranted to investigate if TIPS may be advantageous at an earlier stage of liver dysfunction.

\section{Management of complicated ascites Refractory ascites}

According to the International Club of Ascites (ICA) criteria, a diagnosis of refractory ascites requires intensive diuretic therapy for at least 1 week and a salt-restricted diet of less than $90 \mathrm{mmol} /$ day, mean weight loss of $<0.8 \mathrm{~kg}$ over 4 days and urinary sodium output less than the sodium intake, reappearance of grade 2 or 3 ascites within 4 weeks of initial mobilisation and development of diuretic-induced complications. ${ }^{[12]}$ Refractory ascites occurs in 5\%-10\% of patients with cirrhosis and ascites (more than $90 \%$ of patients have diuretic-intractable ascites) and is associated with a low probability of survival: about $50 \%$ at 6 months. ${ }^{[64]}$

\section{Management of refractory ascites}

Large-volume paracentesis

Repeated LVP plus HA (8 $\mathrm{g}$ for a litre of ascites removed) are recommended as the first-line treatment for refractory ascites. ${ }^{[13]}$ This has been shown to be safe and effective with a low incidence of renal injury and electrolyte abnormalities and lesser systemic and haemodynamic disturbances compared with diuretics. ${ }^{[1]]}$

\section{Diuretics}

According to EASL guidelines, diuretics should be discontinued in patients with refractory ascites who do not excrete $>30 \mathrm{mmol} /$ day of sodium under diuretic treatment. ${ }^{[13]}$

Nonselective beta-blockers

The administration of nonselective beta-blockers (NSBBs) in patients with refractory ascites is a matter of discussion. NSBBs reduce portal pressure and are currently used for primary and secondary prophylaxis of variceal haemorrhage. ${ }^{[65,66]}$ Some reports suggested protective effects with NSBBs in patients with decompensated cirrhosis probably mediated by reduction of intestinal permeability and inflammation, particularly in this advanced stage. ${ }^{[67-69]}$ Illustratively, a recent post hoc analysis of three RCTs explored the co-administration of vaptans 
and NSBBs in patients with ascites: the 52 -week cumulative all-cause mortality was similar in the NSBB user and nonuser groups $(23.2 \%$ vs. $25.3 \%$, adjusted hazard ratio $[\mathrm{HR}]=0.92,95 \%$ CI $0.72-1.18)$. This effect was also confirmed in the subgroup of patients with refractory ascites; however, during follow-up, $29 \%$ of initial NSBB users stopped taking NSBBs, entailing an increased risk of mortality, hospitalisation, variceal bleeding, bacterial infection and/or development of HRS. ${ }^{[70]}$

Conversely, various studies caution the use of NSBBs in situations such as $\mathrm{SBP},{ }^{[71]}$ severe alcoholic hepatitis ${ }^{[72]}$ and refractory ascites. In particular, the Clichy group reported poor survival and increased risk of PPCD among patients on NSBB therapy; in one study, the median survival time was 5 months in patients treated with NSBBs compared with 20 months in patients not treated with NSBBs. ${ }^{[73,74]}$

The mechanism underlying these findings was supposed to be related to the induction of systemic arterial hypotension and exhaustion of cardiac reserve. Furthermore, patients with advanced stages of decompensation often receive higher doses of NSBBs, thus exaggerating the detrimental effects on systemic haemodynamics. Accordingly, a retrospective nationwide study of 3719 Danish patients with cirrhosis found a reduction in mortality for propranolol doses $<160 \mathrm{mg} /$ day (HR 0.4; 95\% CI $0.2-0.8)$, but an increase in mortality for doses $>160 \mathrm{mg} /$ day (HR 2.5; 95\% CI 0.9-6.8). ${ }^{[75]}$ This finding led to the 'window hypothesis', which postulates that NSBBs are associated with higher rates of survival in selected patients with moderate-to-large oesophageal varices, but without refractory ascites, hypotension, SBP, HRS, sepsis or severe alcoholic hepatitis. ${ }^{[76,77]}$

In conclusion, while NSBBs continue to occupy a pivotal role in the treatment of portal hypertension, recent evidence has not only outlined additional, haemodynamically independent beneficial effects in cirrhosis, but also described potentially debilitating effects in advanced stages. According to AASLD and EASL guidelines, physicians should use NSBBs with caution in cirrhotic patients with refractory ascites and discontinue usage if haemodynamic or renal impairment arises. Moreover, carvedilol and highdose propanolol should be avoided. ${ }^{[13,14]}$

\section{Albumin}

Evidence concerning long-term administration of HA in patients with refractory ascites is scant compared to that on uncomplicated ascites. However, an observational study by Di Pascoli and colleagues suggested that mortality may be significantly reduced with the administration of $40 \mathrm{~g}$ twice a week than without $(41.6 \% v s .65 .5 \%$ over a period of 2 years). ${ }^{[7]}$
Transjugular intrahepatic portosystemic shunt

Evidence supporting the use of TIPS in patients with refractory ascites is controversial. Among four RCTs exclusively concerning patients with refractory ascites, one showed that TIPS with bare-metal stents worsens mortality compared with standard treatment, mainly because of the detrimental effect of TIPS in Child-Pugh class C patients. ${ }^{[79]}$ Two RCTs did not find any difference. ${ }^{[00,81]}$ A better survival with TIPS was reported in just one study. ${ }^{[82]}$ Recent evidence assessed the effects of TIPS with polytetrafluoroethylene (PTFE)-covered stent grafts. Two retrospective studies reported better control with covered stent grafts than with bare stent grafts in patients with refractory ascites ${ }^{[83,84]}$ It seems that the development of hepatic encephalopathy and stent thrombosis can be reduced with the use of covered stent grafts. ${ }^{[85,86]}$ Other potential side effects are liver and heart failure. ${ }^{[87,88]}$

A careful selection of patients is crucial to maximise the beneficial effects of TIPS. Score systems have been developed to help clinicians' choice. ${ }^{[88]}$ Indeed, 2012 AASLD guidelines recommend to reserve TIPS for patients who meet the criteria similar to those of published randomised trials. ${ }^{[14]}$

\section{Other treatments}

A substantial portion of patients with refractory ascites are not candidates for TIPS insertion. Several medical treatments such as midodrine, clonidine, terlipressin and tolvaptan have been studied in this scenario, but at present, EASL guidelines do not recommend any of them $;{ }^{[13]}$ conversely, AASLD guidelines suggest the use of midodrine in this setting. ${ }^{[14]}$

The automated low-flow ascites pump (Alfapump ${ }^{\circledR}$ ) system is a subcutaneously implanted pump connected to catheters that transfer ascites from the peritoneal cavity to the bladder, allowing elimination with urine. Alfapump showed efficacy in two RCTs in patients with advanced cirrhosis and refractory ascites, reducing the need for paracentesis by $90 \% \cdot{ }^{[89,90]}$ Conversely, its main side effect and contraindication is renal failure. ${ }^{[91]}$ Alfapump is considered in EASL guidelines, but not in AASLD guidelines. ${ }^{[13,14]}$

\section{Liver transplantation}

EASL guidelines suggest that LT should be considered not only in all patients with refractory ascites, but also in patients with grade 2 or 3 ascites because of their poor prognosis $^{[13]}$ which can greatly improve after LT: $71 \%$ of patients are alive at 10 years. ${ }^{[2]}$

The Child-Pugh classification and, since 2002, MELD score have been used for patient selection and priority. 
Nevertheless, MELD score does not consider the impact of refractory ascites; so, in Europe, it is considered an exception to MELD score as an indication for LT. ${ }^{[33]}$

Conversely, AASLD guidelines suggest to expedite the referral for LT should for patients with refractory ascites only if the patient is otherwise a candidate for it. ${ }^{[14]}$

\section{RENAL IMPAIRMENT AND HRS}

Renal impairment in patients with decompensated cirrhosis consists of chronic kidney disease (CKD) and acute renal failure; the latter term was replaced by the term acute kidney injury (AKI) and is defined by the Kidney Disease Improving Global Outcomes (KDIGO) group as an increase in serum creatinine $\geq 0.3 \mathrm{mg} / \mathrm{dL}$ within $48 \mathrm{~h}$ or a percentage increase $\geq 50 \%$ within 7 days. ${ }^{[94]}$ AKI has three severity stages: in the first stage, serum creatinine increases up to twofold from baseline; stage 1 includes stage $1 \mathrm{~A}$ with serum creatinine $<1.5 \mathrm{mg} / \mathrm{dL}$ and stage $1 \mathrm{~B}$ with serum creatinine $\geq 1.5 \mathrm{mg} / \mathrm{dL}$; in the second stage, it increases up to threefold from baseline and in the third stage, it increases more than threefold from baseline. ${ }^{[95,96]}$ From an aetiologic point of view, AKI is differentiated into prerenal AKI, HRS-AKI, intrarenal or intrinsic AKI, which is represented by acute tubular necrosis (ATN), and post-renal AKI. ${ }^{[97]}$

Overall, HRS is just one of the possible reasons of renal impairment in patients with liver disease; a study observed that it is less common than prerenal or infection-associated kidney injury representing just $13 \%$ of the underlying causes of renal deterioration in this setting. ${ }^{[98]}$ However, the prevalence of HRS in cirrhotic ascites rises to $39 \%$ at 5 years and clearly worsens the prognosis. ${ }^{[99]}$

HRS was historically defined as a functional renal failure caused by intrarenal vasoconstriction in patients with liver disease; moreover, based on the time of development and prognosis, HRS is classified as type 1 and type 2 . Absence of renal parenchymal damage and its potential reversibility are considered as its main characteristics. ${ }^{[12]}$

In recent years, the 'functional' paradigm of HRS has been questioned. The idea that HRS has an exclusive functional nature is now unsustainable. Vasodilatation and inadequate cardiac output, which leads to intrarenal vasoconstriction and renal impairment, was considered the epicentre of pathogenesis, but systemic inflammation and microvascular dysfunction, as well as some degree of parenchymal damage are also considered determinants. ${ }^{[100-102]}$

Second, the historic classification in type 1 and type 2 was recently revised. Type 1 is now called HRS-AKI and fulfills the characteristics of AKI. It occurs in patients with cirrhosis and ascites as well as in patients with acute liver failure in the presence of precipitating factors: not only bacterial infections from any sources (in particular, bacterial translocation from the gut) seem to play a major role in this process, ${ }^{[103,104]}$ but also LVP without adequate albumin administration and excessive administration of diuretics could provoke HRS-AKI. ${ }^{[34,44]}$

Nowadays, the diagnosis of HRS-AKI is based on the revised ICA criteria: 1) presence of cirrhosis and ascites, 2) presence of $A K I, 3)$ no response to diuretic withdrawal and volume expansion with albumin, 4) absence of shock, 5) no nephrotoxic drugs, 6) no macroscopic signs of structural kidney injury (proteinuria, microhaematuria and/ or abnormal renal ultrasonography). ${ }^{[9]}$

Since prerenal-AKI can be recognised by the response to plasma volume expansion, the differential diagnosis between HRS-AKI and ATN-AKI is a challenge. ATNAKI is characterised by signs of parenchymal damage such as microhaematuria and proteinuria, which cannot be present. ${ }^{[105]}$ Novel biochemical markers are under study to solve this problem, and the most promising is neutrophil gelatinase-associated lipocalin (NGAL). ${ }^{[106,107]}$ Nevertheless, the presence of increased levels of some tubular biomarkers in patients with HRS-AKI may suggest that there is a continuum from HRS to ATN. Type 2 is now called HRS-NAKI (non-AKI) because its main clinical consequence is not acute renal failure, but refractory ascites. ${ }^{[108]}$ It can be considered the extreme expression of the impairment in circulatory function during the course of cirrhosis. ${ }^{[109]}$ Angeli and colleagues proposed to refer HRS-NAKI either to CKD, defined by a reduction of the glomerular filtration rate (GFR) under $60 \mathrm{~mL} / \mathrm{min}$ developed in more than 3 months (HRS-CKD), or to acute kidney disease, if the reduction developed in less than 3 months without the criteria for AKI (HRS-AKD). ${ }^{[110]}$ HRSAKI and HRS-NAKI should not be seen as a continuum because they are clinically and pathophysiologically independent.

\section{Management of renal impairment and HRS}

When a patient with liver disease suffers from AKI, any potentially leading drug should be stopped, volume replacement therapy should be provided and, in the absence of an evident underlying cause, $1 \mathrm{~g}$ of $20 \% \mathrm{HA} / \mathrm{kg}$ of body weight has to be administered for two consecutive days. ${ }^{[13]}$

Based on EASL guidelines, HRS-AKI should be treated with HA associated with vasoconstrictive drugs. The drug that is the most recognised for this purpose is terlipressin, administered at a dose of $0.5 \mathrm{mg}$ every $4-6 \mathrm{~h}$ or by continuous i.v. infusion at an initial dose of $2 \mathrm{mg} /$ day. HA 
should be administered at the dose $20-40 \mathrm{~g} /$ day $;{ }^{[13]}$ higher doses considered in the treatment of AKI as discussed above have never been studied in patients with HRS-AKI, in particular, in combination with terlipressin. Bearing in mind new theories about the role of systemic inflammation in decompensated cirrhosis and HRS, and the physiologic role of albumin, we may understand the central role of HA administration in this scenario. ${ }^{[111]}$ In one prospective non-randomised trial, reversal of HRS, defined as a serum creatinine level of $<1.5 \mathrm{mg} / \mathrm{dL}$, was significantly higher with terlipressin plus HA than with terlipressin alone $(77 \%$ vs. $25 \%$ ). ${ }^{[52]}$

An alternative vasoconstrictor is noradrenaline, given by continuous i.v. infusion at the dose of $0.5-3 \mathrm{mg} / \mathrm{h}$. This drug is less studied and requires a central line and an intensive care unit setting. ${ }^{[13,14]}$ Seven RCTs compared terlipressin with noradrenaline, but only one study found that terlipressin had better survival than noradrenaline. ${ }^{[12]}$ Terlipressin has not been approved for use in the United States, so it is not mentioned in AASLD guidelines, which suggest the use of octreotide plus midodrine as vasoactive drugs. ${ }^{[14]}$ However, this suggestion is based on the results of small studies, ${ }^{[113,114]}$ and the combination octreotide plus midodrine has been shown to be much less effective than terlipressin in the treatment of HRS in a recent RCT. ${ }^{[115]}$

TIPS has a minor role in HRS-AKI because it is often contraindicated due to disease severity that limits its application $;^{[13]}$ moreover, a recent meta-analysis showed high incidence of hepatic encephalopathy with TIPS. ${ }^{[116]}$ Non-responders to the combination of HA and vasoconstrictors should be considered for renal replacement therapy following the same criteria as in general population. ${ }^{[13]} \mathrm{LT}$ is the best therapeutic option for patients with HRS, regardless of the response to drug therapy; ${ }^{[117]}$ moreover, simultaneous liver-kidney transplantation should be considered for HRS-AKI with no response to drug therapy. ${ }^{[13,14]}$

Based on EASL guidelines, in patients with HRS-NAKI, including HRS-CKD, vasoconstrictors and HA are not recommended despite their efficacy because of the high rate of recurrence probably due to the underlying renal parenchymal damage. ${ }^{[13,118]}$ TIPS may have a role in the management of HRS-NAKI because the frequent association with of refractory ascites, for which the efficacy of TIPS has been described above. ${ }^{[13]}$

Renal replacement therapy and LT, in particular, simultaneous liver-kidney transplantation, can be indicated in patients with cirrhosis and significant $\mathrm{CKD} \cdot{ }^{[13,14]}$
Despite continuous progress in the treatment of HRS, its prognosis remains severe and more therapeutic options are warranted. A recent systematic review and meta-analysis showed that the combination of Tradition Chinese Medicine (TCM) with conventional therapy seems to lower serum creatinine, blood urea nitrogen, bilirubin, plasma ammonia and abdominal circumference; however, the study was invalidated by significant heterogeneity and methodological issues. At present, evidence is scant and TCM cannot be officially suggested as an adjunctive treatment. ${ }^{[119]}$

\section{SPONTANEOUS BACTERIAL PERITONITIS}

SBP is defined as a bacterial infection of ascites without any intra-abdominal source of infection. ${ }^{[120]}$ Any patient with cirrhotic ascites is at risk of SBP, and its prevalence in outpatients is $1.5 \%-3.5 \%$, increasing sensibly in hospitalised patients; moreover, it makes the prognosis of ascites worse (mortality due to SBP is now estimated to be around 20\%). ${ }^{[121]} \mathrm{SBP}$ is highly common in cirrhotic ascites, justifying diagnostic paracentesis in all patients. SBP is diagnosed when the neutrophil count is greater than $250 / \mathrm{mm}^{3}$ in ascitic fluid. Conversely, the positivity of bacterial culture is not essential for diagnosis, considering the high rate of false-negative culture; however, cultures should always be performed because any isolated bacteria can guide antibiotic therapy. Bacterascites is instead defined as a neutrophil count less than $250 / \mathrm{mm}^{3}$, but positive bacterial culture. ${ }^{[13,14]}$

\section{Management of SBP}

Nowadays, major concern about the treatment of SBP gravitates around the alarming increase in the spread of multidrug-resistant (MDR) and extensively drug-resistant (XDR) organisms. ${ }^{[122]}$ Notably, cirrhotic patients are highly susceptible to develop infections by these bacteria due to frequent hospitalisations and antibiotic treatment. ${ }^{[123]}$ The most recent guidelines radically changed the recommendations about the choice of antibiotic treatment, prioritising the probability of infection by MDRs or XDRs; this approach is a major novelty compared with the past. ${ }^{[13]}$

In the setting of community-acquired SBP, third-generation cephalosporin is the first-line antibiotic treatment; ${ }^{[13,14]}$ in particular, cefotaxime is considered the best option because of its high concentration in the ascitic fluid. ${ }^{[124]}$ The 2012 American guidelines also suggest the use of ofloxacine as an alternative to cefotaxime for patients without prior exposure to quinolones. ${ }^{[14]}$ 
In countries with high rates of bacterial resistance, piperacillin/tazobactam or carbapenem should be considered as the first-line option also in a communityacquired setting according to EASL guidelines. ${ }^{[13]}$

For healthcare-associated and nosocomial SBP, EASL guidelines suggest the use of piperacillin/tazobactam in areas with low prevalence of multidrug resistance. Carbapenem should instead be used in areas with high prevalence of extended-spectrum beta-lactamases (ESBLs) producing Enterobacteriaceae, even associated with glycopeptides, daptomycin or linezolid if coexists also high prevalence of gram-positive MDR bacteria. ${ }^{[13]}$ Conversely, AASLD guidelines do not provide specific suggestion to manage empiric antibiotic therapy in nosocomial setting or the presence of risk factors for MDR infections, but just advises to follow local susceptibility testing of bacteria. ${ }^{[14]}$

HA should be administered in combination with antibiotic therapy in order to prevent HRS-AKI occurrence. In a landmark RCT, mortality was reduced from $29 \%$ to $10 \%$ in patients treated with high-dose HA in combination with cefotaxime than on treatment with cefotaxime alone. Treatment with HA was particularly effective in patients with baseline serum bilirubin $\geq 4 \mathrm{mg} / \mathrm{dL}$ or serum creatinine $\geq 1 \mathrm{mg} / \mathrm{dL}$, who, however, represented the majority of enrolled patients. ${ }^{[51]}$

Based on these results, EASL guidelines recommend the administration of $\mathrm{HA}$ at the dose of $1.5 \mathrm{~g} / \mathrm{kg}$ at diagnosis and $1 \mathrm{~g} / \mathrm{kg}$ on day 3 in patients with SBP. ${ }^{[13]}$ Conversely, AASLD guidelines restrict this recommendation to patients with similar characteristics to the subgroup of patients who experienced the maximal benefit in the discussed RCT. ${ }^{[14]}$ Our knowledge about alternative regimens with low-dose HA is scant, since just a few studies investigated this possibility. ${ }^{[125,126]}$

Prophylaxis of SBP with norfloxacin is another important topic. According to guidelines, primary prophylaxis has to be limited to patients with ascitic fluid protein $<1.5 \mathrm{~g} /$ $\mathrm{dL}$ along with impaired renal function or liver failure: ${ }^{[13,14]}$ in these categories, 3-month probability of survival was $94 \%$ with norfloxacin and $62 \%$ with placebo in an RCT. ${ }^{[127]}$ Moreover, patients who recover from an episode of SBP should be considered for $\mathrm{LT}^{[13]}$ besides receiving secondary prophylaxis, which demonstrated to reduce recurrence from $68 \%$ to $20 \%$ in another RCT. ${ }^{[128]}$

As for HRS, TCM was investigated as an adjunctive treatment for SBP. In a recent meta-analysis the additional use of Xuebijing injection seems to improve the efficacy of antibiotics for the treatment of SBP in liver cirrhosis; currently, no official suggestion can be made due to a low level of evidence. ${ }^{[129]}$

\section{HEPATIC HYDROTHORAX}

Hepatic hydrothorax is the accumulation of ascites in the pleural space (mostly the right) sustained by a pressure gradient through embryologic diaphragmatic defects. Hepatic hydrothorax can lead to respiratory failure and can be complicated by spontaneous bacterial pleural empyema; its appearance worsens the prognosis of decompensated cirrhosis. ${ }^{[130]}$

Diagnostic approach begins with the exclusion of cardiopulmonary and primary pleural diseases; moreover, diagnostic thoracentesis is required to rule out bacterial infection. ${ }^{[13,131]}$ Diaphragmatic defects can be identified by magnetic resonance imaging or colour Doppler and contrast-enhanced ultrasonography. ${ }^{[132,133]}$

\section{Management of hepatic hydrothorax}

The management includes diuretics, LVP, TIPS and LT. ${ }^{[13,14]}$ Moreover, pleurodesis can be suggested to patients who are not candidates for LT or TIPS. ${ }^{[13]}$ Different techniques have been considered, including surgical approach with the possibility of concomitant repair of diaphragmatic defects; however, the frequency of complications is high. ${ }^{[134]}$

When no other options are available, therapeutic thoracentesis is required to relieve dyspnoea, but its efficacy is transient and multiple repetition is challenging. ${ }^{[13,135]}$ Chest tube insertion is contraindicated because of the high rate of placement-related complications such as bleeding or pneumothorax, infections, protein loss and renal impairment $;^{[14,136,137]}$ conversely, pigtail tube for drainage seems to have a lower rate of complications. ${ }^{[138]}$ Indwelling pleural catheters (IPC) are tunnelled catheters inserted subcutaneously that are often used in the treatment of malignant pleural effusions; although this option is not mentioned by guidelines, some reports showed a favourable cost-effective ratio. ${ }^{[139,140]}$

\section{Conflict of Interest}

We have no conflicts of interest to disclose.

\section{Author Contribution}

A. Gallo and A. Squizzato contributed to the conception and design. A. Gallo, C. Dedionigi and C. Civitelli wrote the manuscript. A. Squizzato, A. Panzeri and C. Corradi contributed to the language and content editing. The manuscript has been read and finally approved by all the authors. 


\section{REFERENCES}

1. Ge PS, Runyon BA. Treatment of patients with cirrhosis. N Engl J Med 2016; 375: 767-77.

2. Rockey DC, Friedman SL. Hepatic Fibrosis and Cirrhosis. In: Zakim and Boyer's Hepatology. 2012. p. 64-85.

3. Asrani SK, Kamath PS. Natural history of cirrhosis. Curr Gastroenterol Rep 2013; 15: 308.

4. Schuppan D, Afdhal NH. Liver cirrhosis. Lancet 2008; 371: 838-51.

5. Ginés P, Quintero E, Arroyo V, Terés J, Bruguera M, Rimola A, et al. Compensated cirrhosis: Natural history and prognostic factors. Hepatology 1987; 7: 122-8.

6. Møller S, Bendtsen F, Henriksen JH. Splanchnic and systemic hemodynamic derangement in decompensated cirrhosis. Can J Gastroenterol 2001; 15: 94-106.

7. Evans TW. Review article: Albumin as a drug - Biological effects of albumin unrelated to oncotic pressure. VAliment Pharmacol Ther 2002; 16 Suppl 5: 6-11.

8. Strauss AW, Donohue AM, Bennett CD, Rodkey JA, Alberts AW. Rat liver preproalbumin: in vitro synthesis and partial amino acid sequence. Proc Natl Acad Sci U S A 1977; 74: 1358-62.

9. Henriksen JH, Stage JG, Schlichting P, Winkler K. Intraperitoneal pressure: Ascitic fluid and splanchnic vascular pressures, and their role in prevention and formation of ascites. Scand J Clin Lab Invest 1980; 40: 493-501.

10. Bernardi M, Moreau R, Angeli P, Schnabl B, Arroyo V. Mechanisms of decompensation and organ failure in cirrhosis: From peripheral arterial vasodilation to systemic inflammation hypothesis. J Hepatol 2015; 63: 1272-84.

11. Moore KP, Wong F, Gines P, Bernardi M, Ochs A, Salerno F, et al. The management of ascites in cirrhosis: Report on the consensus conference of The International Ascites Club. Hepatology 2003; 38: 258-66.

12. Arroyo V, Ginès P, Gerbes AL, Dudley FJ, Gentilini P, Laffi G, et al. Definition and diagnostic criteria of refractory ascites and hepatorenal syndrome in cirrhosis. Hepatology 1996; 23: 164-76.

13. Angeli P, Bernardi M, Villanueva C, Francoz C, Mookerjee RP, Trebicka $\mathrm{J}$, et al. EASL Clinical Practice Guidelines for the management of patients with decompensated cirrhosis. J Hepatol 2018; 69: 406-60.

14. Runyon BA. Introduction to the revised American Association for the Study of Liver Diseases Practice Guideline management of adult patients with ascites due to cirrhosis 2012. Hepatology 2013; 57: 1651-3.

15. Runyon BA, Montano AA, Akriviadis EA, Antillon MR, Irving MA, McHutchison JG. The serum-ascites albumin gradient is superior to the exudate-transudate concept in the differential diagnosis of ascites. Ann Intern Med 1992; 117: 215-20.

16. D’Amico G, Pasta L, Morabito A, D'Amico M, Caltagirone M, Malizia G, et al. Competing risks and prognostic stages of cirrhosis: A 25-year inception cohort study of 494 patients. Aliment Pharmacol Ther 2014; 39: 1180-93.

17. D’Amico G, Garcia-Tsao G, Pagliaro L. Natural history and prognostic indicators of survival in cirrhosis: A systematic review of 118 studies. J Hepatol 2006; 44: 217-31.

18. Llach J, Ginès P, Arroyo V, Rimola A, Titó L, Badalamenti S, et al. Prognostic value of arterial pressure, endogenous vasoactive systems, and renal function in cirrhotic patients admitted to the hospital for the treatment of ascites. Gastroenterology 1988; 94: 482-7.

19. Veldt BJ, Lainé F, Guillygomarc'h A, Lauvin L, Boudjema K, Messner M, et al. Indication of liver transplantation in severe alcoholic liver cirrhosis: Quantitative evaluation and optimal timing. J Hepatol 2002; 36: 93-8.

20. Bernardi M, Santini C, Trevisani F, Baraldini M, Ligabue A, Gasbarrini G. Renal function impairment induced by change in posture in patients with cirrhosis and ascites. Gut 1985; 26: 629-35.

21. Christensen NJ, Wilken C, Clausen J, Pals H. Diuretic treatment in decompensated cirrhosis and congestive heart failure: Effect of posture. Br Med J (Clin Res Ed) 1986; 292: 1351-3.
22. Morando F, Rosi S, Gola E, Nardi M, Piano S, Fasolato S, et al. Adherence to a moderate sodium restriction diet in outpatients with cirrhosis and ascites: A real-life cross-sectional study. Liver Int 2015; 35: 1508-15.

23. Reynolds TB, Lieberman FL, Goodman AR. Advantages of treatment of ascites without sodium restriction and without complete removal of excess fluid. Gut 1978; 19: 549-53.

24. Merli M, Lucidi C, Giannelli V, Giusto M, Riggio O, Falcone M, et al. Cirrhotic patients are at risk for health care-associated bacterial infections. Clin Gastroenterol Hepatol 2010; 8: 979-85.

25. Huisman EJ, Trip EJ, Siersema PD, Van Hoek B, Van Erpecum KJ. Protein energy malnutrition predicts complications in liver cirrhosis. Eur J Gastroenterol Hepatol 2011; 23: 982-9.

26. Merli M, Giusto M, Lucidi C, Giannelli V, Pentassuglio I, Di Gregorio V, et al. Muscle depletion increases the risk of overt and minimal hepatic encephalopathy: Results of a prospective study. Metab Brain Dis 2013; 28: 281-4.

27. Montano-Loza AJ, Meza-Junco J, Prado CMM, Lieffers JR, Baracos VE, Bain VG, et al. Muscle Wasting Is Associated With Mortality in Patients With Cirrhosis. Clin Gastroenterol Hepatol 2012; 10: 166-73, 173, e1.

28. Berzigotti A, Garcia-Tsao G, Bosch J, Grace ND, Burroughs AK, Morillas $\mathrm{R}$, et al. Obesity is an independent risk factor for clinical decompensation in patients with cirrhosis. Hepatology 2011; 54: 555-61.

29. Montano-Loza AJ, Angulo P, Meza-Junco J, Prado CMM, Sawyer MB, Beaumont $\mathrm{C}$, et al. Sarcopenic obesity and myosteatosis are associated with higher mortality in patients with cirrhosis. J Cachexia Sarcopenia Muscle 2016; 7: 126-35.

30. Merli M, Berzigotti A, Zelber-Sagi S, Dasarathy S, Montagnese S, Genton $\mathrm{L}$, et al. EASL Clinical Practice Guidelines on nutrition in chronic liver disease. J Hepatol 2019; 70: 172-93.

31. Fountain JH, Lappin SL. Physiology, Renin Angiotensin System. In: StatPearls [Internet]. Treasure Island (FL): StatPearls Publishing; 2020 Jan. 2020 Jul 27. Available from: http://www.ncbi.nlm.nih.gov/ pubmed/29261862. Access on August 28, 2020.

32. Bernardi M, Servadei D, Trevisani F, Rusticali AG, Gasbarrini G. Importance of plasma aldosterone concentration on the natriuretic effect of spironolactone in patients with liver cirrhosis and ascites. Digestion 1985; 31: 189-93.

33. Santos J, Planas R, Pardo A, Durández R, Cabré E, Morillas RM, et al. Spironolactone alone or in combination with furosemide in the treatment of moderate ascites in nonazotemic cirrhosis. A randomized comparative study of efficacy and safety. J Hepatol 2003; 39: 187-92.

34. Angeli P, Fasolato S, Mazza E, Okolicsanyi L, Maresio G, Velo E, et al. Combined versus sequential diuretic treatment of ascites in nonazotaemic patients with cirrhosis: Results of an open randomised clinical trial. Gut 2010; 59: 98-104.

35. Pockros PJ, Reynolds TB. Rapid diuresis in patients with ascites from chronic liver disease: The importance of peripheral edema. Gastroenterology 1986; 90: 1827-33.

36. Ginès P, Schrier RW. Renal failure in cirrhosis. N Engl J Med 2009; 361: 1279-90.

37. Jalan R, Kapoor D. Reversal of diuretic-induced hepatic encephalopathy with infusion of albumin but not colloid. Clin Sci 2004; 106: 467-74.

38. Qavi AH, Kamal R, Schrier RW. Clinical use of diuretics in heart failure, cirrhosis, and nephrotic syndrome. Int J Nephrol 2015; 2015: 975934.

39. Angeli P, Albino G, Carraro P, Pria MD, Merkel C, Caregaro L, et al. Cirrhosis and muscle cramps: Evidence of a causal relationship. Hepatology 1996; 23: 264-73.

40. Elfert AA, Abo Ali L, Soliman S, Zakaria S, Shehab El-Din I, Elkhalawany W, et al. Randomized placebo-controlled study of baclofen in the treatment of muscle cramps in patients with liver cirrhosis. Eur J Gastroenterol Hepatol 2016; 28: 1280-4.

41. Mallory A, Schaefer JW. Complications of Diagnostic Paracentesis in Patients With Liver Disease. JAMA J Am Med Assoc 1978; 239: 628-30. 
42. Runyon BA. Paracentesis of Ascitic Fluid: A Safe Procedure. Arch Intern Med. 1986;146(11):2259-61.

43. Ginès P, Titó L, Arroyo V, Planas R, Panés J, Viver J, et al. Randomized comparative study of therapeutic paracentesis with and without intravenous albumin in cirrhosis. Gastroenterology 1988; 94: 1493-502.

44. Gines A, Fernandez-Esparrach G, Monescillo A, Vila C, Domenech E, Abecasis $\mathrm{R}$, et al. Randomized trial comparing albumin, dextran 70 , and polygeline in cirrhotic patients with ascites treated by paracentesis. Gastroenterology 1996; 111: 1002-10.

45. Bernardi M, Caraceni P, Navickis RJ, Wilkes MM. Albumin infusion in patients undergoing large-volume paracentesis: A meta-analysis of randomized trials. Hepatology 2012; 55: 1172-81.

46. Hassan M, Azzazy E, Christenson RH. All About Albumin: Biochemistry, Genetics, and Medical Applications. Theodore Peters, Jr. San Diego, CA: Academic Press, 1996, 432 pp, \$85.00. ISBN 0-12-552110-3. Clin Chem 1997; 43: 2014a-2015.

47. Arroyo V, García-Martinez R, Salvatella X. Human serum albumin, systemic inflammation, and cirrhosis. J Hepatol 2014; 61: 396-407.

48. Jalan R, Schnurr K, Mookerjee RP, Sen S, Cheshire L, Hodges S, et al. Alterations in the functional capacity of albumin in patients with decompensated cirrhosis is associated with increased mortality. Hepatology 2009; 50: 555-64.

49. Baldassarre M, Domenicali M, Naldi M, Laggetta M, Giannone FA, Biselli $\mathrm{M}$, et al. Albumin Homodimers in Patients with Cirrhosis: Clinical and Prognostic Relevance of a Novel Identified Structural Alteration of the Molecule. Sci Rep 2016; 6: 35987.

50. Garcia-Martinez R, Andreola F, Mehta G, Poulton K, Oria M, Jover M, et al. Immunomodulatory and antioxidant function of albumin stabilises the endothelium and improves survival in a rodent model of chronic liver failure. J Hepatol 2015; 62: 799-806.

51. Sort P, Navasa M, Arroyo V, Aldeguer X, Planas R, Ruiz-del-Arbol L, et al. Effect of intravenous albumin on renal impairment and mortality in patients with cirrhosis and spontaneous bacterial peritonitis. N Engl J Med 1999; 341: 403-9.

52. Ortega R. Terlipressin therapy with and without albumin for patients with hepatorenal syndrome: Results of a prospective, nonrandomized study. Hepatology 2002; 36: 941-8.

53. Bortoluzzi A, Ceolotto G, Gola E, Sticca A, Bova S, Morando F, et al. Positive cardiac inotropic effect of albumin infusion in rodents with cirrhosis and ascites: Molecular mechanisms. Hepatology 2013; 57: 266-76.

54. Gentilini P, Casini-Raggi V, Fiore G Di, Romanelli RG, Buzzelli G, Pinzani $\mathrm{M}$, et al. Albumin improves the response to diuretics in patients with cirrhosis and ascites: Results of a randomized, controlled trial. J Hepatol 1999; 30: 639-45.

55. Romanelli RG, La Villa G, Barletta G, Vizzutti F, Lanini F, Arena U, et al. Long-term albumin infusion improves survival in patients with cirrhosis and ascites: An unblinded randomized trial. World J Gastroenterol 2006; 12: 1403-7.

56. Caraceni P, Riggio O, Angeli P, Alessandria C, Neri S, Foschi FG, et al. Long-term albumin administration in decompensated cirrhosis (ANSWER): an open-label randomised trial. Lancet 2018; 391:2417-29.

57. Caraceni P, Riggio O, Angeli P, Alessandria C, Neri S, Foschi FG, et al. PS-083-Serum albumin concentration as guide for long-term albumin treatment in patients with cirrhosis and uncomplicated ascites: Lessons from the ANSWER study. J Hepatol 2019; 70: e53.

58. Solà E, Solé C, Simón-Talero M, Martín-Llahí M, Castellote J, GarciaMartínez R, et al. Midodrine and albumin for prevention of complications in patients with cirrhosis awaiting liver transplantation. A randomized placebo-controlled trial. J Hepatol 2018; 69: 1250-9.

59. Lake JR. The role of transjugular portosystemic shunting in patients with ascites. N Engl J Med 2000; 342: 1745-7.

60. Salerno F, Merli M, Riggio O, Cazzaniga M, Valeriano V, Pozzi M, et al. Randomized controlled study of TIPS versus paracentesis plus albumin in cirrhosis with severe ascites. Hepatology 2004; 40: 629-35.
61. Rössle M, Ochs A, Gülberg V, Siegerstetter V, Holl J, Deibert P, et al. A comparison of paracentesis and transjugular intrahepatic portosystemic shunting in patients with ascites. N Engl J Med 2000; 342: 1701-7.

62. Chen RP, Zhu Ge XJ, Huang ZM, Ye XH, Hu CY, Lu GR, et al. Prophylactic use of transjugular intrahepatic portosystemic shunt aids in the treatment of refractory ascites: Metaregression and trial sequential meta-analysis. J Clin Gastroenterol 2014; 48: 290-9.

63. Bureau C, Thabut D, Oberti F, Dharancy S, Carbonell N, Bouvier A, et al. Transjugular Intrahepatic Portosystemic Shunts With Covered Stents Increase Transplant-Free Survival of Patients With Cirrhosis and Recurrent Ascites. Gastroenterology 2017; 152: 157-63.

64. Moreau R, Delègue P, Pessione F, Hillaire S, Durand F, Lebrec D, et al. Clinical characteristics and outcome of patients with cirrhosis and refractory ascites. Liver Int 2004; 24: 457-64.

65. Lebrec D, Poynard T, Hillon P, Benhamou JP. Propranolol for Prevention of Recurrent Gastrointestinal Bleeding in Patients with Cirrhosis: A Controlled Study. N Engl J Med 1981; 305: 1371-4.

66. Pascal JP, Cales P. Propranolol in the Prevention of First Upper Gastrointestinal Tract Hemorrhage in Patients with Cirrhosis of the Liver and Esophageal Varices. N Engl J Med 1987; 317: 856-61.

67. Senzolo M, Cholongitas E, Burra P, Leandro G, Thalheimer U, Patch $\mathrm{D}$, et al. $\beta$-blockers protect against spontaneous bacterial peritonitis in cirrhotic patients: A meta-analysis. Liver Int 2009; 29: 1189-93.

68. Reiberger T, Ferlitsch A, Payer BA, Mandorfer M, Heinisch BB, Hayden H, et al. Non-selective betablocker therapy decreases intestinal permeability and serum levels of LBP and IL-6 in patients with cirrhosis. J Hepatol 2013; 58: 911-21.

69. Mookerjee RP, Pavesi M, Thomsen KL, Mehta G, MacNaughtan J, Bendtsen F, et al. Treatment with non-selective beta blockers is associated with reduced severity of systemic inflammation and improved survival of patients with acute-on-chronic liver failure. J Hepatol 2016; 64: 574-82.

70. Bossen L, Krag A, Vilstrup H, Watson H, Jepsen. Non-selective betablockers and mortality in cirrhosis patients with or without refractory ascites: Post hoc analysis of three large RCT's with 1198 patients. Hepatology 2016; 63: 1968-76.

71. Mandorfer M, Bota S, Schwabl P, Bucsics T, Pfisterer N, Kruzik M, et al. Nonselective $\beta$ blockers increase risk for hepatorenal syndrome and death in patients with cirrhosis and spontaneous bacterial peritonitis. Gastroenterology 2014; 146: 1680-90.e1.

72. Sersté T, Njimi H, Degré D, Deltenre P, Schreiber J, Lepida A, et al. The use of beta-blockers is associated with the occurrence of acute kidney injury in severe alcoholic hepatitis. Liver Int 2015; 35: 1974-82.

73. Sersté T, Francoz C, Durand F, Rautou PE, Melot C, Valla D, et al. Betablockers cause paracentesis-induced circulatory dysfunction in patients with cirrhosis and refractory ascites: A cross-over study. J Hepatol 2011; 55: 794-9.

74. Sersté T, Melot C, Francoz C, Durand F, Rautou PE, Valla D, et al. Deleterious effects of beta-blockers on survival in patients with cirrhosis and refractory ascites. Hepatology 2010; 52: 1017-22.

75. Bang UC, Benfield T, Hyldstrup L, Jensen JEB, Bendtsen F. Effect of propranolol on survival in patients with decompensated cirrhosis: a nationwide study based Danish patient registers. Liver Int 2016; 36 : 1304-12.

76. Krag A, Wiest R, Albillos A, Gluud LL. The window hypothesis: Haemodynamic and non-haemodynamic effects of $\beta$-blockers improve survival of patients with cirrhosis during a window in the disease. Gut 2012; 61: 967-9.

77. Ge PS, Runyon BA. The changing role of beta-blocker therapy in patients with cirrhosis. J Hepatol 2014; 60: 643-53.

78. Di Pascoli M, Fasolato S, Piano S, Bolognesi M, Angeli P. Long-term administration of human albumin improves survival in patients with cirrhosis and refractory ascites. Liver Int 2019; 39: 98-105.

79. Lebrec D, Giuily N, Hadengue A, Vilgrain V, Moreau R, Poynard T, et al. Transjugular intrahepatic portosystemic shunts: Comparison 
with paracentesis in patients with cirrhosis and refractory ascites: A randomized trial. J Hepatol 1996; 25: 135-44.

80. Ginès P, Uriz J, Calahorra B, Garcia-Tsao G, Kamath PS, Del Arbol LR, et al. Transjugular intrahepatic portosystemic shunting versus paracentesis plus albumin for refractory ascites in cirrhosis. Gastroenterology 2002; 123: $1839-47$.

81. Sanyal AJ, Genning C, Rajender Reddy K, Wong F, Kowdley K V., Benner $\mathrm{K}$, et al. The North American study for the treatment of refractory ascites. Gastroenterology 2003; 124: 634-41.

82. Narahara Y, Kanazawa H, Fukuda T, Matsushita Y, Harimoto H, Kidokoro $\mathrm{H}$, et al. Transjugular intrahepatic portosystemic shunt versus paracentesis plus albumin in patients with refractory ascites who have good hepatic and renal function: A prospective randomized trial. J Gastroenterol 2011; 46: 78-85.

83. Maleux G, Perez-Gutierrez NA, Evrard S, Mroue A, Moine O Le, Laleman $\mathrm{W}$, et al. Covered stents are better than uncovered stents for transjugular intrahepatic portosystemic shunts in cirrhotic patients with refractory ascites: A retrospective cohort study. Acta Gastroenterol Belg 2010; 73: 336-41.

84. Tan HK, James PD, Sniderman KW, Wong F. Long-term clinical outcome of patients with cirrhosis and refractory ascites treated with transjugular intrahepatic portosystemic shunt insertion. J Gastroenterol Hepatol 2015; 30: 389-95.

85. Sauerbruch T, Mengel M, Dollinger M, Zipprich A, Rössle M, Panther E, et al. Prevention of Rebleeding from Esophageal Varices in Patients with Cirrhosis Receiving Small-Diameter Stents Versus Hemodynamically Controlled Medical Therapy. Gastroenterology 2015; 149: 660e1-668.e1.

86. Bureau C, Garcia-Pagan JC, Otal P, Pomier-Layrargues G, Chabbert V, Cortez C, et al. Improved Clinical Outcome Using PolytetrafluoroethyleneCoated Stents for TIPS: Results of a Randomized Study. Gastroenterology 2004; 126: 469-75.

87. Stanley AJ, Jalan R, Forrest EH, Redhead DN, Hayes PC. Longterm follow up of transjugular intrahepatic portosystemic stem shunt (TIPSS) for the treatment of portal hypertension: Results in 130 patients. Gut 1996; 39: 479-85.

88. Billey C, Billet S, Robic MA, Cognet T, Guillaume M, Vinel JP, et al. A Prospective Study Identifying Predictive Factors of Cardiac Decompensation After Transjugular Intrahepatic Portosystemic Shunt: The Toulouse Algorithm. Hepatology 2019; 70: 1928-41.

89. Bellot P, Welker MW, Soriano G, Von Schaewen M, Appenrodt B, Wiest $\mathrm{R}$, et al. Automated low flow pump system for the treatment of refractory ascites: A multi-center safety and efficacy study. J Hepatol 2013; 58: 922-7.

90. Stirnimann G, Berg T, Spahr L, Zeuzem S, McPherson S, Lammert F, et al. Treatment of refractory ascites with an automated low-flow ascites pump in patients with cirrhosis. Aliment Pharmacol Ther 2017; 46: 981-91.

91. Solà E, Sanchez-Cabús S, Rodriguez E, Elia C, Cela R, Moreira R, et al. Effects of alfapump ${ }^{\mathrm{TM}}$ system on kidney and circulatory function in patients with cirrhosis and refractory ascites. Liver Transplant 2017; 23: 583-93.

92. Adam R, Karam V, Delvart V, O'Grady J, Mirza D, Klempnauer J, et al. Evolution of indications and results of liver transplantation in Europe. A report from the European Liver Transplant Registry (ELTR). J Hepatol 2012; 57: 675-88.

93. Burra P, Burroughs A, Graziadei I, Pirenne J, Valdecasas JC, Muiesan P, et al. EASL Clinical Practice Guidelines: Liver transplantation. J Hepatol 2016; 64: 433-85.

94. Khwaja A. KDIGO clinical practice guidelines for acute kidney injury. Nephron Clin Pract 2012; 120: c179-c184.

95. Fagundes C, Barreto R, Guevara M, Garcia E, Solà E, Rodríguez E, et al. A modified acute kidney injury classification for diagnosis and risk stratification of impairment of kidney function in cirrhosis. J Hepatol 2013; 59: 474-81.

96. Angeli $\mathrm{P}$, Ginès $\mathrm{P}$, Wong F, Bernardi $\mathrm{M}$, Boyer $\mathrm{TD}$, Gerbes $\mathrm{A}$, et al. Diagnosis and management of acute kidney injury in patients with cirrhosis: Revised consensus recommendations of the International Club of Ascites. Gut 2015; 64: 531-7.
97. Garcia-Tsao G, Parikh CR, Viola A. Acute kidney injury in cirrhosis. Hepatology 2008; 48: 2064-77.

98. Martnllah M, Guevara M, Torre A, Fagundes C, Restuccia T, Gilabert $\mathrm{R}$, et al. Prognostic importance of the cause of renal failure in patients with cirrhosis. Gastroenterology 2011; 140: 488-96.e4.

99. Ginès A, Escorsell A, Ginès P, Saló J, Jiménez W, Inglada L, et al. Incidence, predictive factors, and prognosis of the hepatorenal syndrome in cirrhosis with ascites. Gastroenterology 1993; 105: 229-36.

100. Stadlbauer VP, Wright GAK, Banaji M, Mukhopadhya A, Mookerjee $\mathrm{R}$, Moore K, et al. Relationship Between Activation of the Sympathetic Nervous System and Renal Blood Flow Autoregulation in Cirrhosis. Gastroenterology 2008; 134: 111-9.

101. Van Slambrouck CM, Salem F, Meehan SM, Chang A. Bile cast nephropathy is a common pathologic finding for kidney injury associated with severe liver dysfunction. Kidney Int 2013; 84: 192-7.

102. De Seigneux S, Martin PY. Preventing the progression of AKI to CKD: The role of mitochondria. J Am Soc Nephrol 2017; 28: 1327-9.

103. Fasolato S, Angeli P, Dallagnese L, Maresio G, Zola E, Mazza E, et al. Renal failure and bacterial infections in patients with cirrhosis: Epidemiology and clinical features. Hepatology 2007; 45: 223-9.

104. Wiest R, Lawson M, Geuking M. Pathological bacterial translocation in liver cirrhosis. J Hepatol 2014; 60: 197-209.

105. Trawalé JM, Paradis V, Rautou PE, Francoz C, Escolano S, Sallée $\mathrm{M}$, et al. The spectrum of renal lesions in patients with cirrhosis: A clinicopathological study. Liver Int 2010; 30: 725-32.

106. Belcher JM, Edelstein CL, Parikh CR. Clinical applications of biomarkers for acute kidney injury. Am J Kidney Dis 2011; 57: 930-40.

107. Verna EC, Brown RS, Farrand E, Pichardo EM, Forster CS, Sola-Del Valle DA, et al. Urinary neutrophil gelatinase-associated lipocalin predicts mortality and identifies acute kidney injury in cirrhosis. Dig Dis Sci 2012; 57: 2362-70.

108. Angeli P, Morando F, Cavallin M, Piano S. Hepatorenal syndrome. Contrib Nephrol 2011; 174: 46-55.

109. Arroyo V, Terra $C$, Ginès $P$. Advances in the pathogenesis and treatment of type-1 and type-2 hepatorenal syndrome. J Hepatol 2007; 46: 935-46.

110. Angeli P, Garcia-Tsao G, Nadim MK, Parikh CR. News in pathophysiology, definition and classification of hepatorenal syndrome: A step beyond the International Club of Ascites (ICA) consensus document. J Hepatol 2019; 71: 811-22.

111. Piano S, Schmidt HH, Ariza X, Amoros A, Romano A, Hüsing-Kabar A, et al. Association Between Grade of Acute on Chronic Liver Failure and Response to Terlipressin and Albumin in Patients With Hepatorenal Syndrome. Clin Gastroenterol Hepatol 2018; 16: 1792-800.e3.

112. Arora V, Maiwall R, Rajan V, Jindal A, Muralikrishna Shasthry S, Kumar $\mathrm{G}$, et al. Terlipressin Is Superior to Noradrenaline in the Management of Acute Kidney Injury in Acute on Chronic Liver Failure. Hepatology 2020; 71: 600-10.

113. Angeli P, Volpin R, Gerunda G, Craighero R, Roner P, Merenda R, et al. Reversal of type 1 hepatorenal syndrome with the administration of midodrine and octreotide. Hepatology 1999; 29: 1690-7.

114. Esrailian E, Pantangco ER, Kyulo NL, Hu KQ, Runyon BA. Octreotide/ midodrine therapy significantly improves renal function and 30-day survival in patients with type 1 hepatorenal syndrome. Dig Dis Sci 2007; 52: $742-8$.

115. Cavallin M, Kamath PS, Merli M, Fasolato S, Toniutto P, Salerno F, et al. Terlipressin plus albumin versus midodrine and octreotide plus albumin in the treatment of hepatorenal syndrome: A randomized trial. Hepatology 2015; 62: 567-74.

116. Song T, Rössle M, He F, Liu F, Guo X, Qi X. Transjugular intrahepatic portosystemic shunt for hepatorenal syndrome: A systematic review and meta-analysis. Dig Liver Dis 2018; 50: 323-30.

117. Boyer TD, Sanyal AJ, Garcia-Tsao G, Regenstein F, Rossaro L, Appenrodt $\mathrm{B}$, et al. Impact of liver transplantation on the survival of patients treated for hepatorenal syndrome type 1. Liver Transplant 2011; 17: 1328-32. 
118. Alessandria C, Ottobrelli A, Debernardi-Venon W, Todros L, Cerenzia MT, Martini S, et al. Noradrenalin vs terlipressin in patients with hepatorenal syndrome: A prospective, randomized, unblinded, pilot study. J Hepatol 2007; 47: 499-505.

119. Song T, Guo X, Shao L, Sun M, Romeiro FG, Han D, et al. A systematic review and meta-analysis of treatment for hepatorenal syndrome with traditional Chinese medicine. Transl Gastroenterol Hepatol 2018; 3: 57.

120. Fernández J, Navasa M, Gómez J, Colmenero J, Vila J, Arroyo V, et al. Bacterial infections in cirrhosis: Epidemiological changes with invasive procedures and norfloxacin prophylaxis. Hepatology 2002; 35: 140-8.

121. Piano S, Fasolato S, Salinas F, Romano A, Tonon M, Morando F, et al. The empirical antibiotic treatment of nosocomial spontaneous bacterial peritonitis: Results of a randomized, controlled clinical trial. Hepatology 2016; 63: 1299-309.

122. Magiorakos AP, Srinivasan A, Carey RB, Carmeli Y, Falagas ME, Giske CG, et al. Multidrug-resistant, extensively drug-resistant and pandrugresistant bacteria: An international expert proposal for interim standard definitions for acquired resistance. Clin Microbiol Infect 2012; 18 : $268-81$.

123. Fernández J, Bert F, Nicolas-Chanoine $\mathrm{MH}$. The challenges of multidrug-resistance in hepatology. J Hepatol 2016; 65: 1043-54.

124. Runyon BA, Akriviadis EA, Sattler FR, Cohen J. Ascitic fluid and serum cefotaxime and desacetyl cefotaxime levels in patients treated for bacterial peritonitis. Dig Dis Sci 1991; 36: 1782-6.

125. Elloumi H, Sabbah M, Bibani N, Trad D, Elleuch N, Gargouri D, et al. Effect of low dose albumin administration in spontaneous bacterial peritonitis on renal function and survival. Arab J Gastroenterol 2019; 20: 205-8.

126. Sanglodkar U, Jain M, Vargese J, Kedarisetty C, Venkataraman J. Clinical audit to determine efficacy of daily infusion of low dose of $20 \%$ albumin in combination with antibiotics in patients with spontaneous bacterial peritonitis. Clin Exp Hepatol 2019; 5: 301-7.

127. Fernández J, Navasa M, Planas R, Montoliu S, Monfort D, Soriano G, et al. Primary Prophylaxis of Spontaneous Bacterial Peritonitis Delays Hepatorenal Syndrome and Improves Survival in Cirrhosis. Gastroenterology 2007; 133: 818-24.

128. Ginés P, Rimola A, Planas R, Vargas V, Marco F, Almela M, et al. Norfloxacin prevents spontaneous bacterial peritonitis recurrence in cirrhosis: Results of a double-blind, placebo-controlled trial. Hepatology 1990; 12: 716-24.

129. Han D, Wang R, Yu Y, Sun M, Teschke R, Romeiro FG, et al. Xuebijing Injection Combined with Antibiotics for the Treatment of Spontaneous Bacterial Peritonitis in Liver Cirrhosis: A Meta-Analysis. Evid Based Complement Alternat Med 2018; 2018: 2989846.
130. Strauss RM, Boyer TD. Hepatic hydrothorax. Semin Liver Dis 1997; 17: 227-32.

131. Badillo R, Rockey DC. Hepatic hydrothorax: Clinical features, management, and outcomes in 77 patients and review of the literature. Medicine (Baltimore) 2014; 93: 135-42.

132. Zenda T, Miyamoto S, Murata S, Mabuchi H. Detection of diaphragmatic defect as the cause of severe hepatic hydrothorax with magnetic resonance imaging. Am J Gastroenterol 1998; 93: 2288-9.

133. Tamano M, Hashimoto T, Kojima K, Maeda C, Hiraishi H. Diagnosis of hepatic hydrothorax using contrast-enhanced ultrasonography with intraperitoneal injection of Sonazoid. J Gastroenterol Hepatol 2010; 25: 383-6.

134. Hou F, Qi X, Guo X. Effectiveness and Safety of Pleurodesis for Hepatic Hydrothorax: A Systematic Review and Meta-Analysis. Dig Dis Sci 2016; 61: 3321-34.

135. Shojaee S, Khalid M, Kallingal G, Kang L, Rahman N. Repeat Thoracentesis in Hepatic Hydrothorax and Non-Hepatic Hydrothorax Effusions: A Case-Control Study. Respiration 2018; 96: 330-7.

136. Orman ES, Lok ASF. Outcomes of patients with chest tube insertion for hepatic hydrothorax. Hepatol Int 2009; 3: 582-6.

137. Liu LU, Haddadin HA, Bodian CA, Sigal SH, Korman JD, Bodenheimer $\mathrm{HC}$, et al. Outcome analysis of cirrhotic patients undergoing chest tube placement. Chest 2004; 126: 142-8.

138. Sharaf-Eldin M, Bediwy AS, Kobtan A, Abd-Elsalam S, El-Kalla F, Mansour L, et al. Pigtail Catheter: A Less Invasive Option for Pleural Drainage in Egyptian Patients with Recurrent Hepatic Hydrothorax. Gastroenterol Res Pract 2016; 2016: 4013052.

139. Shah R, Succony L, Gareeboo S. Use of tunneled pleural catheters for the management of refractory hepatic hydrothorax. BMJ Case Rep 2011; 2011: bcr0520114213.

140. Chen A, Massoni J, Jung D, Crippin J. Indwelling Tunneled Pleural Catheters for the Management of Hepatic Hydrothorax. A Pilot Study. Ann Am Thorac Soc 2016; 13: 862-6.

How to cite this article: Gallo A, Dedionigi C, Civitelli C, Panzeri A, Corradi C, Squizzato A. Optimal management of cirrhotic ascites: A review for internal medicine physicians. J Transl Intern Med 2020; 8: 220-36. 